\title{
VFR travel: It is underestimated
}

\author{
Elisa Backer* \\ School of Business, University of Ballarat, PO Box 663, Ballarat, Vic. 3353, Australia
}

\section{A R T I C L E I N F O}

\section{Article history:}

Received 20 January 2011

Accepted 30 January 2011

\section{Keywords:}

VFR travel

Visiting friends and relatives

VFR definition

\begin{abstract}
A B S T R A C T
Visiting Friends and Relatives (VFR) travel is a substantial form of tourism worldwide. In Australia, official data measure VFR in one of two ways - purpose of visit or type of accommodation. However, this is only a measurement of those factors; it is not a measure of the size by volume of VFR travel. Yet tourism practitioners often mistakenly use these data to state the size of VFR travel in their destination. Based on quantitative research undertaken in three contrasting destinations in Australia, estimates for the size of VFR travel in those destinations is provided. These results highlight that using official data for measuring VFR travel will underestimate this segment in any Australian destination. Using the VFR definitional model as a conceptual model, this research has estimated that VFR travel represents $48 \%$ of Australia's total overnight tourism market.
\end{abstract}

(c) 2011 Elsevier Ltd. All rights reserved.

\section{Introduction}

More than twenty years ago, Jackson (1990) raised awareness of VFR travel by asking the question "VFR Tourism: Is it underestimated?" in a seminal paper of that title. Over the past two decades, other researchers have added to the VFR literature, however the question of how underestimated is VFR travel remains. This paper attempts to answer the question raised by Jackson (1990) by showing that VFR travel is underestimated.

In answering the question, this paper will use the term VFR travel rather than VFR tourism. Travel and tourism terms are often used interchangeably to mean the same thing (Page \& Connell, 2009). However, tourism and travel are not the same. Whilst most scholarly work in the field of VFR has used the better-known term 'VFR tourism', it is most likely that the work has captured some travellers, who are not necessarily tourists.

Travellers are not necessarily tourists, depending on which definition for tourism is adopted. There are many different definitions for tourism and tourist. The issue of defining tourism is not simplistic and "firms, industrial and governmental organisations and academics with interests in tourism have tried to formulate definitions which are more precise than that of the dictionary" (Leiper, 1979, p.391). Some definitions are economic, some are technical, whilst others are holistic (Leiper, 1979). Some definitions will include a parameter of a distance travelled, a length of stay, or a purpose of visit. Therefore, depending on what definition of a tourist is used, a VFR traveller may not qualify as a VFR tourist.

\footnotetext{
* Tel.: +61 35327 9645; fax: +61 353279405 .

E-mail address: e.backer@ballarat.edu.au.
}

According to Leiper (2004) a definition for a tourist also includes "a search for leisure experiences from interactions with features or characteristics of places they choose to visit" (p. 35). A person travelling to a destination to: attend a wedding, assist a daughter to care for a newborn baby, or visit an ailing relative could not be included as a tourist under Leiper's (2004) definition, and it is likely that many people would agree that people in those scenarios are not a 'tourist'. Those people in the scenarios above would identify themselves as travelling for the purpose of visiting friends and relatives and fall under the official data as VFR travellers. However, they are not tourists. They are travellers. Thus, the term VFR travel is deliberately selected for this paper to appreciate that it is more accurate. For, it cannot be stated with certainly that all respondents included in this research were tourists. However, they were all travellers.

\section{Literature review}

VFR travel is recognised as a large form of tourism worldwide. It is also likely to be the oldest form of travel (Backer, 2011) as travelling to visit friends and relatives has always been socially important. One of the earliest recognised VFR travellers was Celia Fiennes, who between 1685 and 1712 created itineraries around visiting friends and relatives (Leiper, 2004). However, despite being an old form of tourism, scholarly interest in VFR travel is relatively new.

Jackson's (1990) paper sparked research interest in the area of VFR travel throughout the 1990s. A series of research from around the world was generated in the following years. A special edition of an international journal (The Journal of Tourism Studies, 1995) was dedicated to VFR. This special issue combined research on VFR travellers undertaken in Australia, the USA, Canada, the Netherlands, 
and Northern Ireland, to provide a broad analysis of VFR from various parts of the world. All studies (Braunlich \& Nadkarni, 1995; Meis, Joyal, \& Trites, 1995; Morrison, Hsieh, \& O'Leary, 1995; Seaton \& Tagg, 1995; Yuan, Fridgen, Hsieh, \& O'Leary, 1995) found that VFR travel represented a significant part of the overall travel market in those parts of the world. The interest that was generated in the immediate years following Jackson's (1990) article resulted in a realisation that VFR travel had been previously neglected and underestimated (Braunlich \& Nadkarni, 1995; Hay, 1996; King, 1996; McKercher, 1994; 1995; Morrison, Hsieh, \& O'Leary, 1995; Seaton \& Tagg, 1995; Seaton, 1994; Seaton \& Palmer, 1997; Yaman, 1996).

Whilst Jackson's (1990) seminal article is now more than two decades old, it still serves as a reminder that many people who are VFR travellers may not actually identify themselves as VFR travellers. They may quite rightly state that they are on holiday. Therefore, official data that measures VFR travel by purpose of visit will underestimate the size of VFR travel.

This point is only part of the problem. Official data are not a tool for measuring the size of VFR travel. In Australia, official tourism data present VFR in two ways - by purpose of visit or by accommodation type. These data are mistakenly used to state the size of VFR travel, but they were not intended for that purpose. After all, VFR travel was originally developed as a residual category for trips that could not be classified into other categories (Hay, 2008). As such, it is not possible to know the size of VFR travel on a global level. In fact, it is not even possible to know the true size of VFR travel in Australia or at a destination due to definitional issues.

This definitional issue was raised by Backer (2010a) who explained that whilst VFR travel is rarely defined in the extant literature, definitions that have been offered are not consistent. VFR is commonly categorised by purpose of visit, but it can also be categorised by accommodation type (Seaton \& Palmer, 1997). Different percentages will be attained depending on which classification is used, and neither should be considered a comprehensive definition. In a number of cases (for example Hu \& Morrison, 2002; Lee, Morrison, \& Lheto, 2005), no definition was provided but the authors stated that data were collected by purpose of visit, which reveals an assumed definition for VFR travel in this manner. Yuan et al. (1995) defined a VFR traveller in such a way, stating that a "VFR traveller is one who reported visiting friends and relatives as the major purpose for the trip" (p. 19). Similarly, McKercher (1995) stated "that the primary purpose of most participants in this type of travel is to visit with their friends and relatives is axiomatic" (p. 246).

VFR travel has also been defined by their accommodation (Boyne, 2001; King, 1994; Kotler, Bowen, \& Makens, 2006). King (1994) stated that VFR travel is categorising visitors by the type of accommodation that they used. Boyne, Carswell, and Hall (2002) proposed that "a VFR tourism trip is a trip to stay temporarily with a friend or relative away from the guest's normal place of residence, that is, in another settlement or, for travel within a continuous settlement, over $15 \mathrm{~km}$ one-way from the guests' home" (p. 246). Similarly, Kotler et al. (2006) stated that "VFR, as the name suggests, are people that stay in the homes of friends and relatives" (p. 748)

However, not all VFR travellers who stay with friends and relatives state a VFR travel purpose (Jackson, 1990; 2003). Not all people who travel for VFR purposes stay with friends and relatives (Backer, 2010a). Therefore, purpose of visit definitions will capture different people than accommodation definitions will. A more inclusive definition is that "VFR travel is a form of travel involving a visit whereby either (or both) the purpose of the trip or the type of accommodation involves visiting friends and/or relatives" (Backer, 2007, p.369).

To illustrate the problems of only using accommodation type or purpose of visit definitions, official data can be observed (Table 1). When reviewing official data for details on VFR travel, the
Table 1

Visitors in Australia 2008-09.

\begin{tabular}{lll}
\hline & $\begin{array}{l}\text { Purpose of visit VFR } \\
\text { share of visitors }\end{array}$ & $\begin{array}{l}\text { Accommodation VFR } \\
\text { share of visitors }\end{array}$ \\
\hline New South Wales & $34 \%$ & $39 \%$ \\
Victoria & $34 \%$ & $38 \%$ \\
Queensland & $31 \%$ & $37 \%$ \\
South Australia & $32 \%$ & $39 \%$ \\
Western Australia & $31 \%$ & $40 \%$ \\
Northern Territory & $11 \%$ & $17 \%$ \\
Tasmania & $27 \%$ & $34 \%$ \\
Australian Capital Territory & $33 \%$ & $37 \%$ \\
Australia & $32 \%$ & $38 \%$ \\
\hline
\end{tabular}

Source: adapted from Tourism Research Australia, 2010

proportion of visitor nights for VFR purpose of visit is typically different to the proportion of VFR by accommodation type. Based on Australian State and Territory data (Table 1), VFR proportions based on purpose of visit in each state/territory is lower than VFR by accommodation type.

Neither the proportions in the purpose of visit column nor the proportions in the accommodation type column can be used to state the size of VFR travel in those States and Territories. Neither column captures all VFR travellers, therefore understating the size of this form of travel. That is, not all travellers staying with friends or relatives will self-classify themselves as VFR, instead identifying themselves as a holidaymaker (Jackson, 2003). In addition, not all travellers staying with friends or relatives will have a VFR purpose of visit. Therefore the data considering the number of travellers staying with friends or relatives will necessarily underestimate the size of VFR travel.

Similarly, not all VFR travellers stay with the friends or relatives they have travelled to see (Braunlich \& Nadkarni, 1995; Lehto, Morrison, \& O'Leary, 2001; Seaton, 1994). Some people travel to a destination for the specific purpose of visiting a friend or relative but stay in commercial accommodation rather than with that friend or relative. The percentage of visitors in commercial accommodation who are actually VFR travellers has been reported to be between $8.7 \%$ and 10.5\% (Backer, 2010a). Therefore, data presenting VFR by accommodation type will also underestimate the size of VFR travel. This poses definitional problems. Seaton and Palmer (1997) recognised this problem and highlighted that VFR trips by accommodation were more than double the size of those that had been defined by purpose of visit. The lack of a clear understanding of the numbers of VFR travellers hides the significance of this segment of travel, which has ramifications for allocation of resources and marketing campaigns.

In order to measure the size of VFR travel it is first necessary to understand that there are three different types of VFR travellers. Referring to official data by purpose of visit or accommodation type will only provide the measurement of two of those three groups. To understand the size of VFR travel in a destination, the three VFR types would need to be ascertained and aggregated. Backer (2010b) used a matrix to explain this (Fig. 1). The first of these three types are PVFRs - 'pure' VFRs who stay with friends and relatives and state VFR as their main purpose of visit (Backer, 2010b). These are represented by a 'tick' in the left hand top box. Secondly, there are CVFRs Commercial accommodation VFRs who stay in commercial accommodation but who have come to the destination with a VFR purpose of visit (Backer, 2010b). These travellers are represented by the tick in the top right hand box. There are also EVFRs - who are in a sense 'exploiting' VFRs as they are staying with friends and relatives but visiting them is not their main purpose of visit (Backer, 2010b). These VFR travellers are depicted by the tick in the bottom left hand box. This category will also include those VFR travellers who stay with their 


\begin{tabular}{|l|l|l|}
\cline { 2 - 4 } \multicolumn{1}{c|}{} & $\begin{array}{l}\text { Accommodation: } \\
\text { Friends \& family }\end{array}$ & $\begin{array}{l}\text { Accommodation: } \\
\text { Commercial }\end{array}$ \\
\hline $\begin{array}{l}\text { Purpose } \\
\text { of Visit: } \\
\text { VFR }\end{array}$ & PVFRs & \\
\hline $\begin{array}{l}\text { Purpose } \\
\text { of Visit: } \\
\text { Non-VFR }\end{array}$ & CVFRs & \\
\hline & EVFRs & \\
\hline
\end{tabular}

Fig. 1. VFR definitional model. Source: (Backer, 2010b, p. 45). friends or relatives but do not consider themselves to be VFR travellers as they identify themselves as holidaymakers (Jackson, 1990, 2003).

Since VFR travellers may travel to a destination specifically to visit friends or relatives and select commercial accommodation, the official data measurement of VFR travel by accommodation will leave out this type of VFR traveller. In addition, VFR by purpose of visit data will leave out those people who are staying with their friends and relatives but have provided a non-VFR purpose of travel. Therefore, official data do not provide a measurement for the size of VFR travel, as it only captures two VFR types rather than an aggregation of the three VFR types.

\section{Method}

The aim of this research paper was to look at the measurement of VFR travel in three different destinations in Australia to investigate whether any patterns emerged in the three VFR types, using the VFR definitional model (Fig. 1) as the conceptual framework. Three destinations were used for this research - the popular tourist

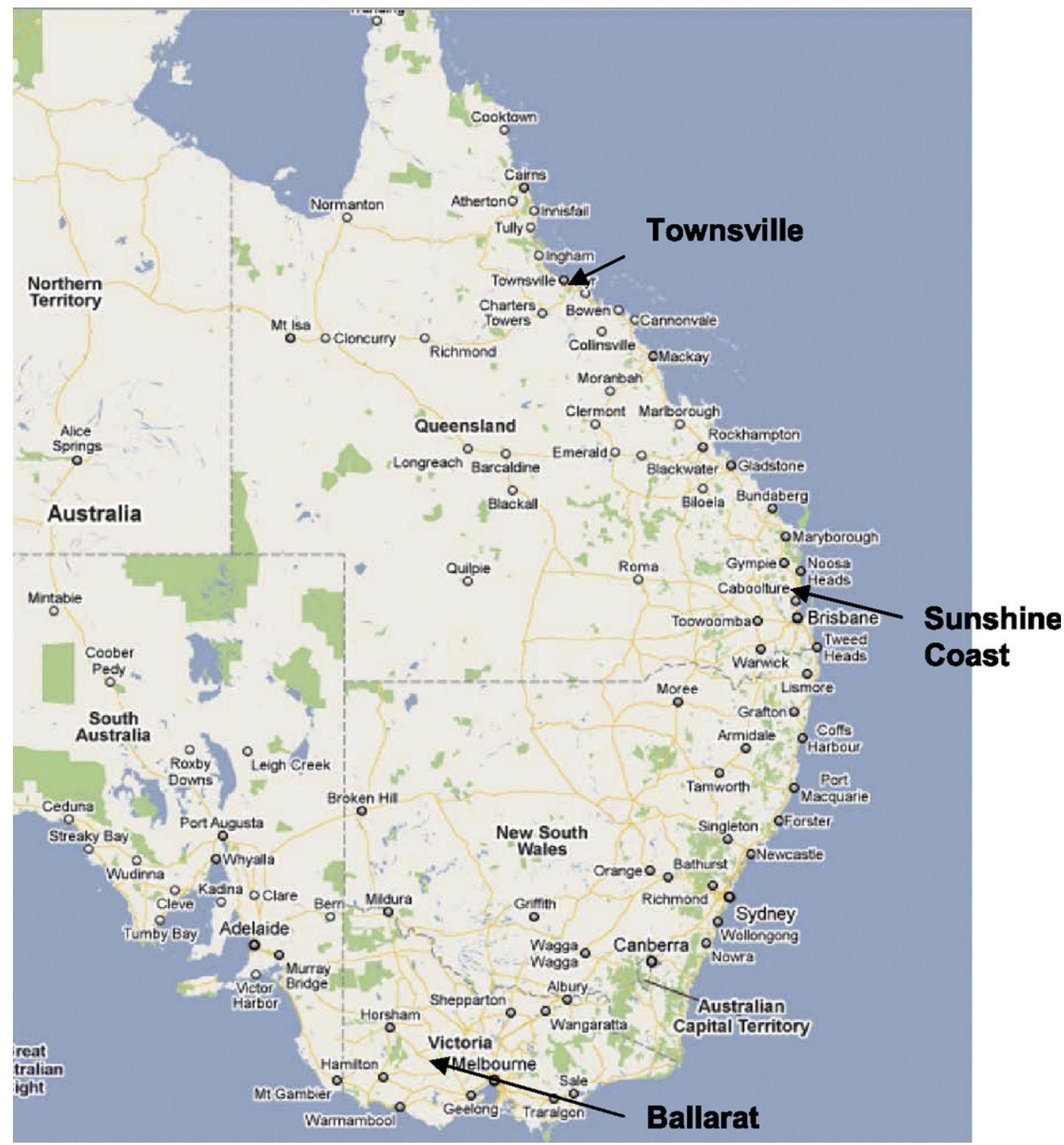

Fig. 2. Destinations used for study zones. Source: Adapted from Google Maps, 2010. 
destination, the Sunshine Coast, the smaller but still popular Townsville, and the inland Victorian city of Ballarat (Fig. 2).

These destinations were selected based on resources and support offered through tourism organisations to enable this research to be undertaken. The destinations offer differences in terms of population, location, climate, and tourism popularity.

The Sunshine Coast is one of the most popular tourist destinations in Australia (Weaver \& Lawton, 2010). One of its features is its pleasant climate, with temperatures in winter ranging from an average of $9.4^{\circ} \mathrm{C}-20.8^{\circ} \mathrm{C}$; and summer temperatures ranging from an average of $21.3^{\circ} \mathrm{C}$ up to $28.7^{\circ} \mathrm{C}$ (Bureau of Meteorology, 2010). It has a range of attractions including beaches, national parks, the Glasshouse Mountains, markets, Australia Zoo, and Underwater World. It also has reputable golf courses and hosts major events. The Sunshine Coast has its own airport to take domestic and international flights.

Townsville has a hotter climate with winter temperatures ranging from an average of $13.6{ }^{\circ} \mathrm{C}$ up to $25.1{ }^{\circ} \mathrm{C}$; and summer temperatures averaging between $24.3{ }^{\circ} \mathrm{C}$ and $31.5{ }^{\circ} \mathrm{C}$ (Bureau of Meteorology, 2010). It also has its own airport, which handles both domestic and international arrivals. Popular tourist features include beaches, Magnetic Island, Castle Hill, as well as access to the Great Barrier Reef.

Ballarat is an inland city that relies on nearby Melbourne's airport (about a 90 min drive away) for tourist arrivals who are not from the self-drive market. Its climate is much colder than the other two destinations. It has average winter temperatures that range from $3.2{ }^{\circ} \mathrm{C}$ up to $10.0{ }^{\circ} \mathrm{C}$; whilst summer temperatures range from an average of $10.8{ }^{\circ} \mathrm{C}$ up to $25.1{ }^{\circ} \mathrm{C}$ (Bureau of Meteorology, 2010). Ballarat's main tourist attraction is the open-air museum, Sovereign Hill.

Despite the differences in the three selected destinations for this research, VFR travel is important to all three regions. The proportions of VFR travellers by purpose of visit and accommodation for those three destinations, based on the official data, are provided in Table 2. Whilst VFR travel can be seen to be a substantial share of visitors based on purpose of visit or accommodation type data, the size of VFR travel cannot be determined without aggregating the three VFR types.

Quantitative research was identified as appropriate for this research. A street survey was developed, and visitors who were staying at least one night in the region were asked what type of accommodation they were staying in, as well as to identify their primary purpose of visit. This allowed visitors to be disaggregated according to the VFR definitional model (Fig. 1).

In each of the three destinations, surveying took place across a range of locations to try to capture a wider range of visitor types and reduce survey bias associated with any particular area. Locations included main streets, shopping precincts, visitor information centres, as well as natural and man-made attractions. Both domestic and international visitors were captured in the surveys. Research assistants would approach people walking towards them to ask if they would participate in a visitors' survey. Responses were recorded via a clip-board system with paper-based surveys filled in by the research assistants. In the Sunshine Coast, after each survey was filled in, the next person approaching the interviewer would be

Table 2

Visitors in Australia 2008-09.

\begin{tabular}{lll}
\hline & $\begin{array}{l}\text { Purpose of visit VFR } \\
\text { share of visitors }\end{array}$ & $\begin{array}{l}\text { Accommodation VFR } \\
\text { share of visitors }\end{array}$ \\
\hline Sunshine Coast & $28 \%$ & $31 \%$ \\
Ballarat & $45 \%$ & $42 \%$ \\
Townsville & $25 \%$ & $36 \%$ \\
\hline
\end{tabular}

Source: Adapted from Tourism Research Australia, 2010 approached. In Townsville and Ballarat, every third person was approached. Thus, convenience surveying was used in the Sunshine Coast whilst probability sampling was used in the other two destinations. The different sampling techniques are considered inconsequential to the results obtained, particularly given the larger sample size obtained in the Sunshine Coast where convenience surveying was used.

The total number of overnight visitor surveys collected in the Sunshine Coast was 738, of which 229 were VFR travellers (across the three types) and 509 were non-VFR travellers. In Ballarat, 254 visitor surveys were collected, comprising 98 VFR travellers and 156 non-VFR travellers. A total of 132 visitor surveys were collected in Townsville with 64 being VFR travellers and 68 being non-VFR travellers. Whilst a larger sample size was desired in Townsville, resourcing could only be maintained for the final three months in 2009 and there was difficulty in gathering visitor surveys during that time.

Surveying occurred in each region over certain months (Sunshine Coast: January to May; Ballarat: May-July; Townsville: October-December), and as such may have resulted in biases of certain types of visitors - particularly in terms of tourist generating regions. However, it is not expected that these would have any significant impact on the relative proportions of VFR types.

Data from each region were disaggregated into one of the four visitor types from the matrix (Fig. 1) in order to formulate a picture of what proportion of VFR travellers fitted into each VFR type. The purpose of using the definitional model as a framework was to gauge whether similarities concerning VFR travellers could be drawn across different regions. Extrapolating emergent patterns to other regions through using Tourism Research Australia data could determine an estimate for the size of VFR travel in destinations in Australia.

\section{Results}

The results for this research are provided in this section. Table 3 through to 5 outline the associated sample sizes for each VFR type based on the VFR definitional model. No attempt was made to ascertain the proportion of VFR travellers amongst the total visitor market in those three destinations. Resources and time restrictions could not encompass a large enough sample size to undertake that analysis. As the focus of this research was to gather VFR data, surveying of non-VFR travellers ceased once the end of the surveying period neared to focus exclusively on gathering VFR data to optimise time. Therefore, the proportion of VFR travellers of the total number of visitors in each region is not known.

Instead, this research endeavoured to capture a sample size of both VFR and non-VFR travellers, and understand what proportion of VFR travellers may fit into each VFR type. Whilst non-VFR travel behaviour was not relevant to this research, it was gathered as part of the research and may be considered relevant for further research. For example, further research could compare and contrast non-VFR travellers against an aggregation of VFR travellers to further enhance knowledge in the field.

As shown in Table 3, the predominant VFR type in the Sunshine Coast was PVFRs - those 'pure' VFR travellers that stated a VFR

Table 3

VFR category sample sizes in the Sunshine Coast based on VFR Travel definitional model.

\begin{tabular}{lll}
\hline Accommodation: friends/family & $\begin{array}{l}\text { Accommodation: } \\
\text { commercial }\end{array}$ \\
\hline Purpose of visit: VFR & $n=124(54 \%)$ PVFRs & $n=60$ (26\%) CVFRs \\
Purpose of visit: Non-VFR & $n=45(20 \%)$ EVFRs & $n=509$ non-VFRs \\
\hline
\end{tabular}


Table 4

VFR category sample sizes in Ballarat based on VFR Travel Definitional Model.

\begin{tabular}{lll}
\hline & $\begin{array}{l}\text { Accommodation: } \\
\text { friends/family }\end{array}$ & $\begin{array}{l}\text { Accommodation: } \\
\text { commercial }\end{array}$ \\
\hline Purpose of visit: VFR & $n=62(63 \%)$ PVFRs & $n=22(22 \%)$ CVFRs \\
Purpose of visit: Non-VFR & $n=14(14 \%)$ EVFRs & $n=156$ non-VFRs \\
\hline
\end{tabular}

purpose of visit and also stayed with friends and relatives. This group, whilst dominant, represented 54\% of the total VFR group. The second largest VFR group was CVFRs - those VFR travellers who stated a VFR purpose of visit but stayed in commercial accommodation. This represented $26 \%$ of the VFR group at the Sunshine Coast. The smallest represented group (20\%) comprised those VFR travellers who stayed with friends and relatives but provided a non-VFR purpose of visit response (EVFRs).

Table 4 provides the results for VFR travellers in Ballarat. Similar to the Sunshine Coast, the dominant group was PVFRs. This represented $63 \%$ of the total VFR group. Again, like the Sunshine Coast, VFR travellers staying in commercial accommodation were the second largest VFR type, representing $22 \%$ of the total VFR group. The smallest VFR group was EVFRs (14\%).

The details for visitors in Townsville are provided in Table 5. The results for this destination were different to Ballarat and the Sunshine Coast with the largest represented VFR group being those who were staying in commercial accommodation (45\%). PVFR travellers were almost as large (44\%), whilst, similar to the other two destinations, the smallest group (11\%) was EVFRs.

\section{Discussion}

Despite the Sunshine Coast and Ballarat having the least in common as destinations out of the three regions, the VFR typology mix was similar. Townsville data revealed a different VFR mix, with a higher proportion of VFR travellers utilising commercial accommodation. With the smaller sample size for Townsville, it is acknowledged that once the data were disaggregated into the three VFR types, the small numbers assigned to each VFR type became problematic. The high proportion of VFR travellers staying in commercial accommodation could have been boosted by anomalies and as such the results can only be considered to be an indicator. However, it is noteworthy that Townsville may encounter a high proportion of VFR travellers using commercial accommodation due to its demographics. The Australian Army maintains a very strong presence in Townsville. Townsville Enterprise Limited has been actively running a VFR campaign throughout 2009 and 2010 believing that its strong army presence does lend the region towards attracting a high proportion of VFR travellers. Townsville is also home to a younger population with students at James Cook University and is popular for those on fly in/fly out contracts at the mines. Therefore, there are several different groups that may not have suitable accommodation to host visiting friends and relatives. As such, it is possible that Townsville has a particularly high proportion of VFR travellers that use commercial accommodation (CVFRs).

Table 5

VFR category sample sizes in Townsville based on VFR Travel Definitional Model.

\begin{tabular}{lll}
\hline & $\begin{array}{l}\text { Accommodation: } \\
\text { friends/family }\end{array}$ & $\begin{array}{l}\text { Accommodation: } \\
\text { commercial }\end{array}$ \\
\hline Purpose of visit: VFR & $n=28(44 \%)$ PVFRs & $n=29(45 \%)$ CVFRs \\
Purpose of visit: Non-VFR & $n=7(11 \%)$ EVFRs & $n=68$ non-VFRs \\
\hline
\end{tabular}

Table 6

Calculations of size of VFR travel.

\begin{tabular}{lrrrrr}
\hline & $\begin{array}{c}\text { PVFRs }+\begin{array}{l}\text { Total o/n } \\
\text { visitors }\end{array} \\
\end{array}$ & & Formula used & $\begin{array}{l}\text { Calculated } \\
\text { number } \\
\text { of all VFRs }\end{array}$ & $\begin{array}{l}\text { Calculated } \\
\text { number } \\
\text { of CVFRs }\end{array}$ \\
\hline Sunshine Coast & 796,000 & $2,553,000$ & $1 / 0.74 \times 796,000$ & $1,075,676$ & 279,676 \\
Ballarat & 193,000 & 464,000 & $1 / 0.77 \times 193,000$ & 250,649 & 57,649 \\
Townsville & 364,000 & 999,000 & $1 / 0.55 \times 364,000$ & 661,818 & 297,818 \\
\hline
\end{tabular}

Despite the emergent VFR typology differences between Townsville compared to the other two regions, the proportion of VFR travellers who used commercial accommodation was high in all three destinations. A minimum of $22 \%$ of VFR travellers stayed in commercial accommodation across the three regions. Thus, VFR travel can not be perceived as offering no benefit to accommodation industries. The results also highlight that the official data cannot be used for a measurement for VFR travel. Whether purpose of visit data or type of accommodation data are used, both leave out one of the three groups of VFR travellers. This was apparent in all three destinations, despite those destinations having little in common with each other as tourism destinations.

Therefore, if an estimate for the size by volume of VFR travel in the Sunshine Coast was required, neither $28 \%$ by purpose of visit or $31 \%$ by accommodation (Table 2 ) would be comprehensive; each leaving out one of the VFR types. The total number of travellers that stayed with friends and relatives in 2008-09 was 796,000 and there were 2,553,000 overnight visitors in total (TRA, 2010). Using that figure as a basis for estimating the size of VFR in the Sunshine Coast reveals it to be $1,075,676$ (since 796,000 is only $74 \%$ of the total VFR segment as determined from Table 3). Thus, VFR is estimated to be $42 \%$ of the total overnight tourism market to the Sunshine Coast (see Table 6).

Using the same process, an estimate can also be offered for Ballarat and Townsville. In Ballarat, 193,000 visitors stayed with friends and relatives (TRA, 2010). Based on the VFR types ascertained in Table 4, people who stayed with friends and relatives represented $77 \%$ of the total VFR segment. As such, the total number of VFR travellers is estimated to be 250,649 (see Table 6), which is $54 \%$ of the total overnight market $(464,000)$.

In the northern region, which incorporates Townsville, 364,000 visitors stayed with friends and relatives during 2008-2009 (TRA, 2010). This represents 55\% of the number of all VFR travellers, based on the findings in Table 5. Using this as an estimate to calculate the number of VFR travellers reveals the figure may be as high as 661,818 (see Table 6). This represents $66 \%$ of the total domestic overnight market $(999,000)$. However, it is acknowledged that the smaller sample size used for this region is a limitation. In addition, the official statistical zone incorporates

Table 7

Estimated size of domestic overnight VFR travel Domestic travel.

\begin{tabular}{lll}
\hline & $\begin{array}{l}\text { Accommodation VFR } \\
\text { share of visits }\end{array}$ & $\begin{array}{l}\text { Estimated size } \\
\text { of VFR }\end{array}$ \\
\hline New South Wales & $39 \%$ & $49 \%$ \\
Victoria & $38 \%$ & $48 \%$ \\
Queensland & $37 \%$ & $46 \%$ \\
South Australia & $39 \%$ & $49 \%$ \\
Western Australia & $40 \%$ & $50 \%$ \\
Northern Territory & $17 \%$ & $22 \%$ \\
Tasmania & $34 \%$ & $42 \%$ \\
Australian Capital Territory & $37 \%$ & $46 \%$ \\
Australia & $38 \%$ & $48 \%$ \\
\hline
\end{tabular}

Source: adapted from Tourism Research Australia, 2010. 
a territory beyond Townsville so this estimate is considered limited in these ways.

\section{Conclusions and implications}

The findings of this research indicate that official data are not a reliable measure for determining the size of VFR travel. The official data measure how many people stayed with friends and relatives and how many people stated a VFR purpose of visit. Since neither figure represents all three VFR types, each of these data will necessarily leave out a VFR category and underestimate the size of VFR.

A more reliable measure may be derived by recognising that the official data are only a proportion of the total number of VFR travellers. That is, in the Sunshine Coast, VFR by accommodation represents $74 \%$ of all VFR travellers, with $26 \%$ of VFR travellers staying in commercial accommodation. In Ballarat, $22 \%$ of VFR travellers stayed in commercial accommodation. In Townsville, 45\% of VFR travellers stayed in commercial accommodation. With $22 \%$ being the lowest proportion of VFR travellers, staying in commercial accommodation, a figure of $20 \%$ is selected to be applied to other destinations, to be conservative in the estimates. Using this baseline, an estimate for the size of VFR can be gained for any region in Australia using official TRA data. Applying this formula to the data from Table 1 reveals VFR estimates as outlined in Table 7.

As outlined in Table 7, the conservatively estimated size of VFR in each state and territory indicates that VFR travel is almost half the size of the total overnight travel market in Australia. Whilst VFR travel is already understood to be a sizable segment in Australia, this research highlights that the actual size is bigger than has been understood. As such, in answer to Jackson's (1990) question, VFR travel is underestimated.

It is recognised that this research provides only estimates to measure VFR travel. However, it should be appreciated that such research represents the first known attempt to measure the size of VFR travel in the Australian states and territories. Tourism organisations that are requiring tourism data for their region will typically utilise secondary data from Tourism Research Australia. They assume that the proportions of VFRs by purpose of visit and by accommodation are the measurements and use either one of those data or both.

This research has therefore contributed to literature and industry in several key ways. Firstly, this is the first known attempt to measure the size of VFR travel across state tourism organisation boundaries. Secondly, the findings reinforce the important role that VFR travel holds in commercial accommodation, which has received little research. As such, the findings promote a very important point in terms of industry relevance; that VFR may be a unique and profitable market to target in many destinations. Thirdly, this paper serves as a reminder of a key point raised over twenty years ago by Jackson (1990), that VFR is underestimated. Not only is VFR underestimated because not all VFR travellers state a VFR purpose of visit. VFR is also underestimated because there is no system that attempts to aggregate the three VFR types and estimate the size of VFR travel in any destination.

These research findings have outlined that VFR can be measured through using the three distinct VFR types. The findings revealed that the proportion of VFR travellers who stayed in commercial accommodation was a minimum of $22 \%$ in the three destinations examined. As such, using a conservative estimate of $20 \%$ in any region in Australia, VFR travel is calculated to be $48 \%$ of Australia's overnight travel market. This is larger than has previously been recognised. Whilst limitations of this research are recognised, and have been outlined through this paper, this research has made an important contribution in raising awareness of the true size of VFR travel in Australia. It is hoped that this research may serve as a stimulator for further research in the future to test these findings in more detail.

\section{References}

Backer, E. (2007). VFR travel - an examination of the expenditures of VFR travellers and their hosts. Current Issues in Tourism, 10(4), 366-377.

Backer, E. (2010a). Opportunities for commercial accommodation in VFR. International Journal of Tourism Research, 12(4), 334-354.

Backer, E. (2010b). VFR travel: An assessment of VFR versus non-VFR travellers. USA: VDM Verlag Dr. Müller.

Backer, E. (2011). VFR travellers of the future. In I. Yeoman, C. Hsu, K. Smith, \& S. Watson (Eds.), Tourism and demography (pp. 74-84). Oxford: Goodfellow Publishers.

Boyne, S. (2001). Hosts, friends and relatives in rural Scotland: VFR tourism market relationships explored. In L. Roberts, \& D. Hall (Eds.), Rural tourism and recreation: Principles to practice (pp. 41-43). Wallingford: Cabi Publishing.

Boyne, S., Carswell, F., \& Hall, D. (2002). Reconceptualising VFR tourism: friends, relatives and migration in a domestic context. In C. M. Hall, \& A. M. Williams (Eds.), Tourism and migration: new relationship between production and consumption (pp. 241-256). Netherlands: Kluwer.

Braunlich, C., \& Nadkarni, N. (1995). The importance of the VFR market to the hote industry. The Journal of Tourism Studies, 6(1), 38-47.

Bureau of Meteorology. (2010). Climate statistics for Australian locations. Retrieved from. http://www.bom.gov.au/climate/averages/tables/cw_040861.shtml.

Google Maps. (2010). Google Maps Australia. http://maps.google.com.au/?ie=UTF8 $\& l l=-26.863281,147.612305 \& s p n=29.664917,39.506836 \& z=5 \& p w=2$ Retrieved from.

Hay, B. (1996). An insight into the European experience: a case study on domestic VFR tourism within the UK. In H. Yaman (Ed.), VFR Tourism: Issues and implications. Proceedings from the conference held at Victoria University of technology (pp. 52-66).

Hay, B. (2008). An exploration of the differences in the volume and value of visiting friends and visiting relatives tourism in the UK. CAUTHE 2008 Where the bloody hell are we?, 1-10.

Hu, B., \& Morrison, A. M. (2002). Tripography: can destination use patterns enhance understanding of the VFR market? Journal of Vacation Marketing, 8(3), 201-220. doi: $10.1177 / 135676670200800301$.

Jackson, R. (1990). VFR tourism: is it underestimated? The Journal of Tourism Studies, $1(2), 10-17$.

Jackson, R. (2003). VFR Tourism: is it underestimated? The Journal of Tourism Studies, 14(1), 17-24.

King, B. (1994). What is ethnic tourism? An Australian perspective. Tourism Management, 15(3), 173-176.

King, B. (1996). VFR - A future research agenda. In H. Yaman (Ed.), VFR tourism: Issues and implications proceedings from the conference held at Victoria University conference, Victoria, Australia (pp. 85-89).

Kotler, P., Bowen, J., \& Makens, J. (2006). Marketing for hospitality and tourism (4th ed.). New Jersey: Pearson Education.

Lee, G., Morrison, A. M., \& Lheto, X. (2005). VFR: is it really marginal? A financial consideration of French overseas travellers. Journal of Vacation Marketing, 11(4), 340-356. doi:10.1177/1356766705056630.

Lehto, X. Y., Morrison, A. M., \& O'Leary, J. T. (2001). Does the visiting friends and relatives' typology make a difference? A study of the international VFR market to the United States. Journal of Travel Research, 40(2), 201-212. doi:10.1177/ 004728750104000211.

Leiper, N. (1979). The framework of tourism: towards a definition of tourism, tourist, and the tourist industry. Annals of Tourism Research, 6(4), 390-407.

Leiper, N. (2004). Tourism management (3rd ed.). Frenchs Forest: Pearson Education.

McKercher, B. (1994). Report on a study of host involvement in VFR travel to Albury Wodonga. Albury-Wodonga.

McKercher, B. (1995). An examination of host involvement in VFR travel. In Proceedings from the national tourism and hospitality conference 1995 ( $\mathrm{pp}$. 246-255). Council for Australian University Tourism and Hospitality Education.

Meis, S., Joyal, S., \& Trites, A. (1995). The U.S. repeat and VFR visitor to Canada: come again eh! The Journal of Tourism Studies, 6(1), 27-37.

Morrison, A. M., Hsieh, S., \& O'Leary, J. (1995). Segmenting the visiting friends and relatives market by holiday activity participation. The Journal of Tourism Studies, 6(1), 48-63.

Page, S., \& Connell, J. (2009). Tourism: A modern synthesis (3rd ed.). China: Cengage Learning.

Seaton, A. V., \& Tagg, S. (1995). Disaggregating friends and relatives in VFR tourism research: the Northern Ireland evidence 1991-1993. The Journal of Tourism Studies, 6(1), 6-18.

Seaton, A. (1994). Are relatives friends? Reassessing the VFR category in segmenting tourism markets. In A. Seaton (Ed.), Tourism: The state of the art (pp. 316-321) Chichester: Wiley.

Seaton, A., \& Palmer, C. (1997). Understanding VFR tourism behaviour: the first five years of the United Kingdom tourism survey. Tourism Management, 18(6), 345-355.

Tourism Research Australia. (2010). Regional tourism profiles 2008/09. Canberra. Weaver, D., \& Lawton, L. (2010). Tourism management (4th ed.). Milton: Wiley.

Yaman, H. (1996). VFR tourism: issues and implications. In Proceedings from the conference held at Victoria University of Technology. Victoria: Victoria University of Technology.

Yuan, T., Fridgen, J., Hsieh, S., \& O'Leary, J. (1995). Visiting friends and relatives trave market: the Dutch case. The Journal of Tourism Studies, 6(1), 19-26. 